\title{
Energy Efficiency of Femtocell Deployment in Combined Wireless/Optical Access Networks
}

Authors: Slavisa Aleksic, Margot Deruyck, Willem Vereecken, Wout Joseph, Mario Pickavet and Luc Martens

(C) Elsevier (2012). This is an authors' copy of the work. It is posted here by permission of Elsevier for your personal use. Not for redistribution. The definitive version is scheduled for publication in Computer Networks in 2013. The DOI of the final publication is 10.1016/j.comnet.2012.12.013. 


\title{
Energy Efficiency of Femtocell Deployment in Combined Wireless/Optical Access Networks
}

\author{
Slavisa Aleksic ${ }^{\mathrm{a}}$, Margot Deruyck ${ }^{\mathrm{b}}$, Willem Vereecken ${ }^{\mathrm{b}}$, Wout Joseph $^{\mathrm{b}}$, Mario Pickavet $^{\mathrm{b}}$, and Luc Martens ${ }^{\mathrm{b}}$ \\ ${ }^{a}$ Vienna University of Technology, Institute of Telecommunications, Favoritenstrasse 9-11/389, 1040 Vienna, Austria \\ Email: slavisa.aleksic@tuwien.ac.at \\ ${ }^{b}$ Department of Information Technology (INTEC) of Ghent University - iMinds, Gaston Crommenlaan 8, B-9050 Gent, Belgium \\ Email: \{margot.deruyck, willem.vereecken,wout.joseph, mario.pickavet, luc.martens\}@intec.ugent.be
}

\begin{abstract}
Optical/wireless convergence has become of particular interest recently because a combined radio wireless and optical wired network has the potential to provide both mobility and high bandwidth in an efficient way. Recent developments of new radio access technologies such as the Long Term Evolution (LTE) and introduction of femtocell base stations open new perspectives in providing broadband services and applications to everyone and everywhere, but the instantaneous quality of radio channel varies in time, space and frequency and radio communication is inherently energy inefficient and susceptible to reflections and interference. On the other hand, optical fiber-based networks do not provide mobility, but they are robust, energy efficient, and able to provide both an almost unlimited bandwidth and high availability.

In this paper, we analyze the energy efficiency of combined wireless/optical access networks, in which LTE technology provides ubiquitous broadband Internet access, while optical fiber-based technologies serve as wireless backhaul and offer high-bandwidth wired Internet access to business and residential customers. In this contest, we pay a particular attention to femtocell deployment for increasing both access data rates and area coverage. The paper presents a novel model for evaluating the energy efficiency of combined optical/wireless networks that takes into account the main architectural and implementational aspects of both RF wireless and optical parts of the access network. Several hypothetical network deployment scenarios are defined and used to study effects of femtocell deployment and power saving techniques on network's energy efficiency in urban, suburban and rural areas and for different traffic conditions.
\end{abstract}

Keywords: Communication networks, energy efficiency, access networks, optical/wireless convergence

\section{Introduction}

Nowadays, cellular wireless networks grow rapidly in both number of subscribers and amount of traffic. According to the International Telecommunication Union (ITU-T), the number of wireless broadband subscriptions worldwide overtook the total number of fixed broadband subscriptions for the first time in 2008, and currently, there are $60 \%$ more wireless broadband subscriptions than the wired ones [1]. Since the number of deployments and the penetration of the 3rd generation $(3 \mathrm{G})$ radio technologies has been rapidly increasing and the data rate per user of all $3 \mathrm{G}$ technologies has

\footnotetext{
${ }^{*}$ Received: June 19, 2012

Revised: December 19, 2012

Accepted: December 20, 2012

Preprint submitted to Computer Networks

been continuously improving, the requirements on the network providing backhaul for the wireless infrastructure are increasing too. New radio interfaces are already capable of providing hundreds of Mbit/s over a single radio link between a base station and a user. The introduction of the so called 4th generation radio technologies (4G), which is also known as "Beyond 3G" (B3G) and new applications for smart phones and other mobile devices will lead to even more user traffic and significantly stronger needs for both high capacity and a better support of advanced software applications.

Due to the current developments, the wireless backhaul is experiencing the major paradigm shift from the currently commonly used solutions based on relatively low data-rate Plesiochronous Digital Hierarchy (PDH) leased lines for connecting $2 \mathrm{G} / 3 \mathrm{G}$ cell sides to base station controllers to a more flexible, broadband, and both 
energy- and cost-effective solution using an fiber-based network. As optical access networks are able to provide a very high bandwidth practically almost independent on distance and a high energy efficiency [2], it seems that a combination of mobile wireless access with optical access networks is a very promising integrated approach for a sustainable and efficient next generation ubiquitous access network. Wireless cellular and optical wired access networks provide synergies and complementary features. The main benefits of using a kind of wireless access are mobility and ubiquity while optical access networks provide high data rates, low power consumption and robustness.

Despite its ever increasing capacity and ability to support new bandwidth intensive applications, high energy consumption of the access network infrastructure demands particular attention. It has been shown that access networks are the largest contributor to the network related electricity consumption and corresponding greenhouse gas emissions (GHGs) [3, 4, 5]. Among all access solutions, mobile access technologies have the lowest energy efficiency [6], i.e., they consume the highest energy per user and per bit of data transmitted. Although user mobile devices are designed for very low energy consumption because of limited capacity and size of batteries, base stations of cellular networks are not energy efficient. This is due to the fact that base stations are constantly kept active and because of the inherently energy-inefficient transmission method used for wireless access, in which a large percentage of the power emitted from antenna is not used for communication but rather spread out in the air. Therefore, any effort in increasing the energy efficiency of the wireless networks could lead to significant energy savings. For example, introduction of femtocells could lead to a more efficient use of the transmitted power. Femtocell base stations provide higher data rates with lower power signals because of reduced cell size and increased spectral efficiency. Thus, the femtocell base stations consume less energy than, e.g., macrocell or microcell ones for the same data rate $[7,8,9,10]$. Concurrently, the limited range means a larger number of base stations to be deployed, but also a higher flexibility. Different mechanisms such as selective putting in the sleep mode of individual base stations during their inactivity times can thus easily be implemented. Indeed, various architectures and algorithms have already been proposed basing on such methods and approaches to increase the energy efficiency of the wireless access infrastructure [10, 11].

On the one hand, the increase of both data rate per user of mobile networks and number of base stations demands a higher capacity and a larger number of net- work terminals in the wireless backhaul network. On the other hand, optical access networks have the potential to provide very high energy efficiency, large distances and high data rate access for a large number of users [5]. Therefore, a logical path towards future highperformance access networks is an efficient combination of radio and optical access technologies in order to realize an integrated and efficient wireless/optical access network.

In this paper, we study the energy efficiency of a combined wireless/wired network employing Long Term Evolution (LTE) for wireless access and a standard optical access technology for wired Internet access and for connecting the mobile base stations to the network core. The optical wired access technologies we consider here are either point-to-point ( $\mathrm{p}-\mathrm{t}-\mathrm{p})$ Ethernet or a kind of Passive Optical Network such as Gigabit PON (GPON) that is based on the Asynchronous Transfer Mode (ATM) or EPON based on the Ethernet.

For this purpose, we developed a model that takes into account the main architectural and implementational aspects of both LTE and optical access. Several hypothetical deployment scenarios for combined wireless/optical networks are defined with the particular focus on a possible deployment of femtocell base stations. The femtocell deployment scenarios are analyzed by means of achievable energy efficiency. Although there are several studies that consider energy efficiency of RF wireless [7, 9, 10, 11, 12, 13] and optical wired $[2,3,4,5,6,14]$ access as separate networks, there is still no study, to the best of the authors' knowledge, that investigate a combined wireless/optical network form the energy point of view.

The paper is organized as follows. Section 2 reviews current trends in technologies and approaches for access networks. Section 3 describes the considered architecture of the combined wireless/optical access network and the model that is developed for evaluating the energy efficiency of wireless/optical access networks. Considered scenarios and main parameters are presented in Section 4, while some selected results obtained by the model are presented and discussed in Section 5. Finally, Section 6 summarizes the paper and draws conclusions.

\section{Current Trends in Access Networks}

One of the emerging radio technologies nowadays is LTE (Long Term Evolution) [15]. In December 2009, world's first publicly available LTE-service was started in Scandinavia [16]. It promises downlink peak rates of at least $100 \mathrm{Mbit} / \mathrm{s}$. This is achieved by using among 
others SOFDMA (Scalable Orthogonal Frequency Division Multiple Access) as multiple access technique. SOFDMA is derived from OFDMA (Orthogonal Frequency Division Multiple Access) and supports a wide range of bandwidths to flexibly address the need for various spectrum allocation and application requirements. LTE supports variable bandwidths from $1.4 \mathrm{MHz}$ to $20 \mathrm{MHz}$ and operates in the $2.6 \mathrm{GHz}$ frequency range. In the future, LTE will probably also use the $800 \mathrm{MHz}$ band (digital dividend frequencies). Release 10 of LTE, also known as LTE-Advanced [17], is a candidate technology for IMT-Advanced, which defines the systems beyond IMT-2000.

There have been recently a large number of projects concentrating on fiber-based optical access for broadband transmission of data generally named Fiber-ToThe-x (FTTx). There are different options for FTTx depending on how near to the subscriber the fiber reaches. A typical example is the fiber-to-the-home (FTTH), which means that the optical signal reaches the end subscriber's equipment situated in the subscriber home. Other examples are FTTB (Fiber-ToThe-Building), FTTC (Fiber-To-The-Curb), and FTTN (Fiber-To-The-Node). When looking at the topology of the access network, it can be either ring or tree or a combination of these two topologies. Additionally, interconnections can be based on unidirectional or bidirectional fibers in a point-to-point ( $\mathrm{p}-\mathrm{t}-\mathrm{p}$ ) or point-to-multipoint (p-t-mp) arrangement. Since recently, the number of FTTH connections has been remarkably growing. For example, in the United States, the annual growth rate was above $100 \%$ between 2002 and 2008 [18]. While still relatively strong, FTTH growth has slowed somewhat since 2008. There are currently about 20.9 million homes in North America where a fiber connection is technically available and approximately 7 millions homes actually connected with lit fiber [18]. In Japan, the number of FTTH connections has exceeded that of ADSL in January 2007 [19]. In Asia, there are currently around $78 \%$ of the world's FTTH subscribers. In the first half of 2009, the growth rates in China and Taiwan were $167 \%$ and $25 \%$, respectively [20].

There are various ways how to combine wireless networks with optical fiber-based access [21, 22]. Maybe the most intuitive way would be to use the so-called Radio over Fiber (RoF) method, in which radio frequency signals are modulated directly on the optical carrier and transmitted through a fiber optic link. Different signals, frequency bands, modulation formats and coding schemes can be combined and transmitted over a single fiber [22]. Although this technique can potentially provide transparency in the optical domain to wireless standards and services and a high energy efficiency through minimizing the number of required components between the mobile user and central office of network provider, it suffers, however, from impairments on the signal such as noise, distortion, and dispersion. Additionally, although considered as an option for the so-called converged next-generation FTTH networks, the currently deployed optical access infrastructure and devices do not support this option. Therefore, combining wireless access with a standard FTTH technology such as GPON, EPON or p-t-p optical Ethernet seems to be the most probable option for an efficient short and medium term support of fast penetration of the highspeed LTE technology.

\section{Combined Wireless/Optical Access Network}

This section presents the architecture of the considered combined wireless/optical access network and the method used to estimate its energy efficiency.

\subsection{Network Architecture}

The architecture of the considered access network is shown in Figure 1. The combined network can be divided into three different planes, i.e., three different networks that coexist in the same spacial area and share both the customers residing in this area and the available resources in the central office. The bottom plane represents the wired optical access network that provides very high data rate Internet access to business and residential customers. We assume here two different types of wired optical access, namely a point-to-point network based on optical Ethernet, i.e., an active optical access network with Ethernet switches deployed in the field, and a point-to-multipoint optical access network, i.e. a passive optical network (PON). The middle plane represents the optical backhaul of the $3 \mathrm{G} / 4 \mathrm{G}$ cellular wireless network, which itself is represented by the upper plane in the figure. In this study, we consider the same access technologies for both optical wired access and wireless backhaul networks. We assume that the network termination equipment belonging to these two networks can be housed in the same rack unit and may share the same uplink of the switch in the central office. However, the network terminal equipment of the two networks is never connected to the same port of the aggregation switch because synchronization and service levels required by the wired and wireless parts of the network are different. For this reason we assume that optical network terminals (ONTs) of the wireless backhaul and those of the wired optical access network are connected to different optical line terminals (OLTs). 


\subsection{Description of the Network Model}

In order to determine both network design parameters and average data rates per user, we define some technology and topology related parameters and limitations as depicted in Figure 2. For cellular networks we have to define the minimum required link budget for a particular configuration of the base station and selected transmission mode. Using a suitable propagation model we can determine the range of a base station $\left(D_{R L}\right)$ and the maximum achievable data rate for users that are located at the distance $D_{R L}$ from the antenna $\left(D R_{R, \max }\right)$ that can be provided by the chosen technology and particular network design. The limited capacities of both links and switches in the access networks have also to be taken into account. For example, the finite capacity of the base station network interface $\left(C_{B S}\right)$, the maximum capacity of the Ethernet switch $\left(C_{S W}\right)$ in the field in case of an active optical access network and the upstream data rate $\left(D R_{P O N, \text { max }}\right)$ of the feeder fiber in case of a passive optical network limit the achievable data rate per user in an overload situation. Similarly, the uplink capacity of the aggregation switch in the central office $\left(C_{C O}\right)$ sets an upper limit on the aggregated data rate within the network segment that is served by the switch.

The architectural and technological aspects as well as the limitations described above are considered in the model when determining the achievable average access data rates for wired and wireless network users. Additionally, statistical data about network and service usage, i.e., the time dependent network utilization, number of wired and wireless subscribers and technology penetration represent the input to the model.

As can be seen from Figure 3, the overall model of the combined wireless/opitical access network is di-

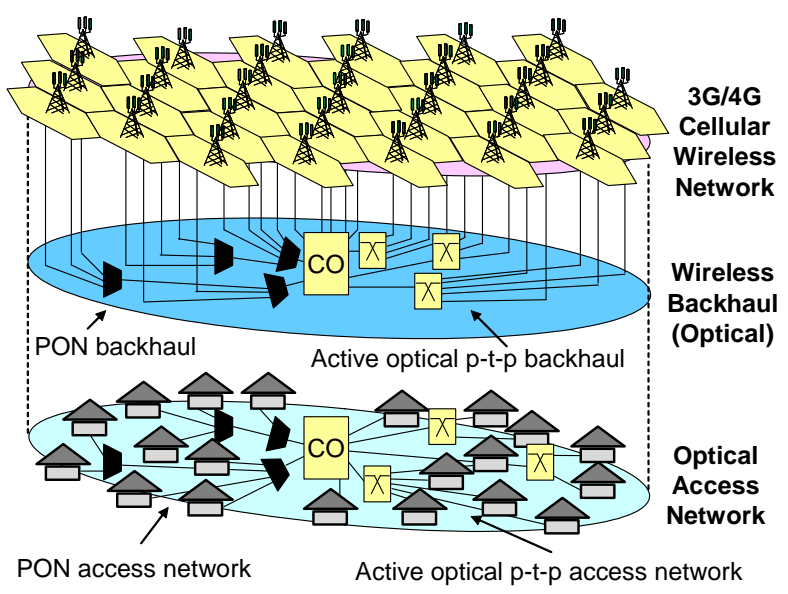

Figure 1: Planes of the combined wireless/optical access network vided into three submodels as shown in Figure 1. The input parameters of both cellular wireless and optical wired network models are: population density in the area under consideration, number of subscribers, network usage, the percentage of subscribers that are active at each particular time, and user traffic (both DS (DownStream) and US (Up-Stream)). According to the technology and design-related parameters and considering the usage of the network during the day, we obtain the achievable aggregate traffic, and thus the achievable average data rate per user for each of the two submodels (the wireless and the wired access network submodels). In the case of the submodel for wireless backhaul, its input parameters are the output values of the wireless submodel such as the average number of active users per cell, the number of active base stations and average data rates (both US and DS) per base station. Note that in case of a coexistence of two or more cell types, i.e., macro-, micro-, pico- and femtocells, the aforementioned parameters are given per cell type. In order to keep the complexity of the model as low as possible, we decided not to model the transmission of data packets through the network, but instead to deal with time-ofthe-day dependent average data rates per user. Following this approach we are able to perform traffic analysis without using a packet-based, event-driven simulator, which would most probably lead to a complex and less scalable implementation. Hence, in the simulator developed in the course of this study, the amount of traffic generated and consumed by network users within a time interval serves to calculate average data rates for this interval, which are then used to determine the volume of traffic to be processed by network elements. The model

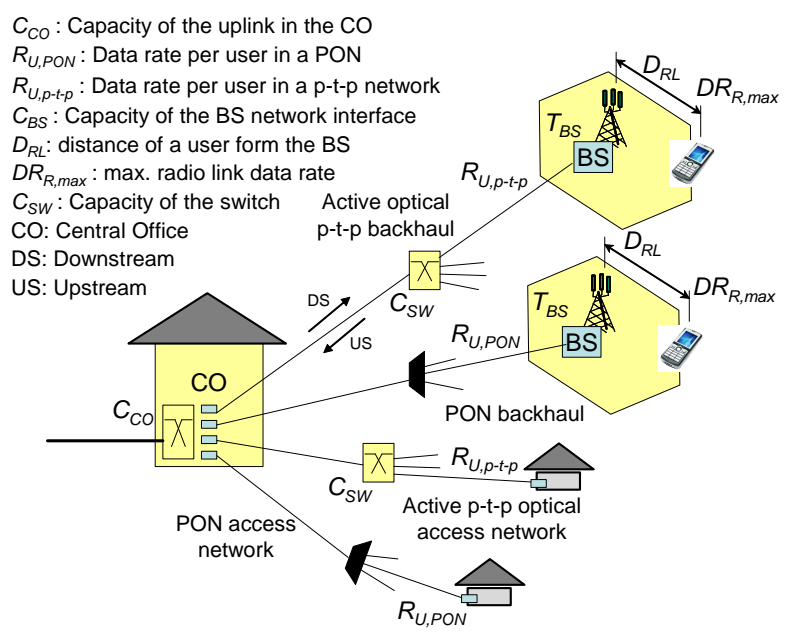

Figure 2: Technology and topology related aspects and limitations 


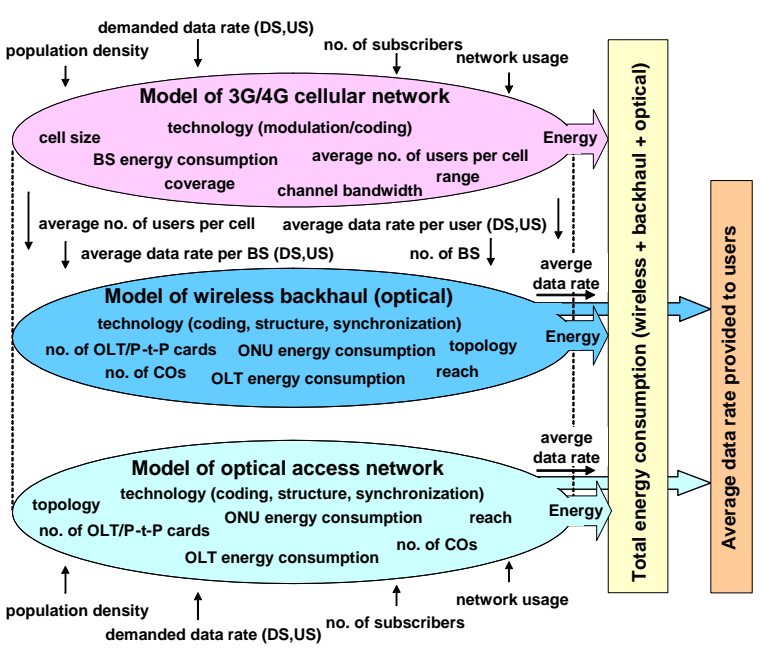

Figure 3: Model overview

is implemented in a modular manner, where first design and configuration parameters are calculated according to input parameters such as the number of users, area to be covered, technology peculiarities, aimed coverage, etc. Then, aggregate traffic at each network element and for every time interval during a day is determined and the intermediate results are exchanged between the network submodels. Thus, this approach allows a quasidynamic modeling of the combined wireless/optical access network while keeping the complexity of the simulator at a reasonable level. Finally, the total average data rates and energy consumption are calculated and used to obtain energy efficiency for different deployment scenarios. A detailed description of the scenarios considered in this study can be found in Section 4.

The instantaneous energy consumption of the network is obtained by summing up the energy consumption values of all active network elements within a specified period of time. The average overall energy consumption is then obtained by averaging the values of energy consumption obtained for different time periods during the day. Note that the power consumption of enduser equipment is not taken into account because we set the system boundaries at the network terminals. Thus, we consider the network equipment including the optical network terminals and radio base stations, but excluding personal computers (PCs), laptops and mobile devices such as cellular phones, smartphones and tablet PCs. Additionally, the mobile devices are optimized for low energy consumption and usually consume just a small fraction of the energy consumed by base stations and fixed-access equipment [23]. Since we consider the use of different power saving methods in the model for

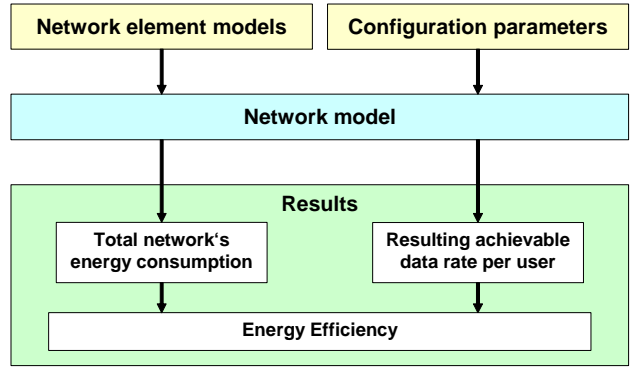

Figure 4: Schematic representation of the model for evaluation of energy efficiency of access networks.

energy consumption, we differentiate between several levels of power consumption that correspond to several operation modes of the equipment.

Network element models, as presented in the next two subsections, are used together with configuration parameters in the network model, in which technological, topological and configuration parameters are combined in order to obtain the total network's energy consumption and corresponding achievable data rate per user for a given scenario and traffic demand. Energy efficiency is obtained by dividing the resulting data rate per user by the energy consumed by a single user. The modelling approach is depicted in Figure 4. The models we use to estimate power consumption of network elements for optical wired and cellular wireless networks are presented in the two following subsections.

\subsubsection{Model of optical access networks}

Energy consumption of optical network elements is estimated by first defining generic structures of different equipment located at both network provider and user premisses as shown in Figure 5. A concentration element in the central office $(\mathrm{CO})$ of network providers usually comprises an uplink interface, a switching module and a number of optical line terminal (OLT) cards. Optionally, it can comprise cooling equipment. All other components that may be needed to implement some additional functions or features are represented by the block "Misc". As already mentioned, we consider in this study the standard p-t-p optical Ethernet and two options of passive optical networks (PONs), namely EPON and GPON. GPON uses an ATM (Asynchronous Transfer Mode) based data transport, and thus is able to provide both constant bit rate (CBR) services for an efficient transport of cellular traffic and synchronization required by radio access networks. In contrast, the standard Ethernet based p-t-p and PONs do not inherently support such type of service. However, recent developments of the carrier-grade Ethernet were forc- 
a)

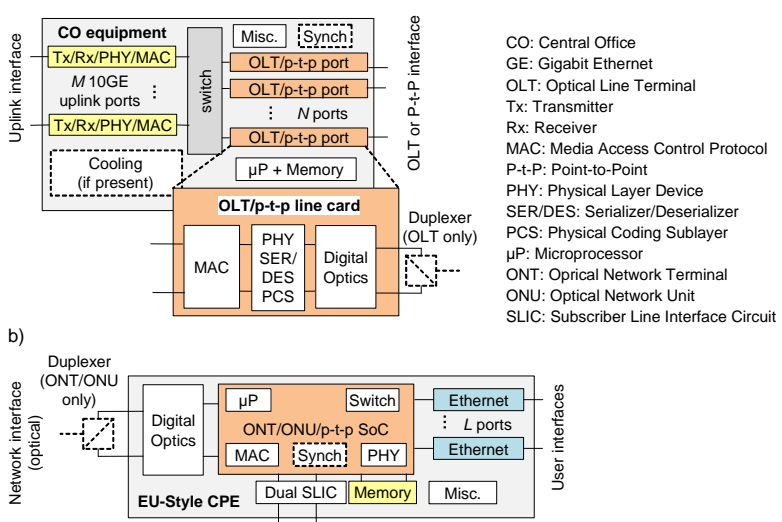

Figure 5: High-level representation of optical access network equipment located at a) network provider premisses and b) customer premisses

ing the inclusion of methods for synchronization in the Ethernet such as the precision time protocol (PTP), version 2 (IEEE1588-2008) and the Synchronous Ethernet (SyncE) as recommended by ITU-T G.8261. For this reason, the structure of optical network elements for wireless backhaul differ from that for wired access because they must meet stronger synchronization requirements, which can be provided by the inclusion of an additional component (Synch) that implements both SyncE and IEEE1588v2 functions.

The energy consumption per network element is calculated by considering consumption values of individual functional blocks that can be implemented either in a single specific component or as a part of a large integrated circuit (IC) device. The energy consumption of a functional block is obtained by averaging the consumption values of a number of components currently available on the market. In order to validate our model of network elements, the obtained values for their total power consumption are compared to those given in technical specifications of some commercially available systems. The values used to obtain the total power consumption per network element are shown in Tables 1 and 2, which also contain the maximum achievable net line data rates for each technology, i.e., the specified maximum data rates excluding the line coding overheads. The values of line transceivers' power consumption are typical consumption values for transmission distances of up to 10 $\mathrm{km}$.

The optical network model $[2,5,24,25]$ includes several modules as shown in Figure 6. Parameters used in the model can be grouped into configuration and network-related parameters. Configuration parameters include the number of subscribers per central office, the capacity limitation of the switch in the field $\left(C_{S W}\right)$ and the uplink capacity of the central office $\left(C_{C O}\right)$. Networkrelated parameters are on the one hand the networkspecific topology, the maximum reach of the access network, and the power consumption of the corresponding network elements and on the other hand the maximum upstream and downstream data rates per subscriber that are directly influenced by the applied network configuration and its parameters. A combination of the aforementioned parameters and their values represent the input to the model used for calculation of energy efficiency. The output of the model is the energy efficiency obtained by combining the total power consumption of the network and the resulting achievable data rates per subscriber. Thus, the resulting energy efficiency, i.e., the amount of information transferred through the access network while consuming one Joule of energy, is expressed in Gbit per Joule (Gbit/s/Watt = Gbit/Joule). Note that all data rates are observed at the interface between the physical layer and the data link layer. Thus, the overheads due to coding and modulation are taken into account but not the overheads induced by the data link and the network layer.

The execution of the model for optical wired access networks is carried out in three steps. In the first step, the topology, configuration and number of network line and termination elements are determined on the basis of the technology used, the number of subscribers, the area to be covered and the required access data rates. This first step corresponds to a network design process that takes into account technological and topological limitations as well as requirements set by network users. In the second step, achievable data rates are calculated at each network element according to the user traffic from both wired and wireless parts of the access network and according to the assumptions made for each deployment scenario. At the same time, total network power consumption is obtained by summing up the estimated power consumptions of all active elements. How both the achievable data rates and the total power consumption are determined will be explained later in this chapter. The final step consists of determining energy efficiency by combining the achievable aggregate data rate and the total network power consumption.

In contrast to passive optical networks, where active users have to share the available bandwidth of the feeder fiber, we assume for the p-t-p active optical Ethernet that all users can achieve the maximum data rate provided by the technology between CPEs and the Ethernet switch in the field. The data rate per user in this case is only limited by the maximum capacity of the switch to which 


\begin{tabular}{|l|c|c|}
\hline \multicolumn{1}{|c|}{ network element } & $\begin{array}{c}\text { max. data rate } \\
\text { (DL/UL) [Gbit/s] }\end{array}$ & power \\
\hline \hline GPON (4 OLT pots) & $10 / 10$ & $47 \mathrm{~W}$ \\
\hline 1G-EPON (4 OLT ports) & $10 / 10$ & $45 \mathrm{~W}$ \\
\hline 1G-EPON (4 OLT ports) Synch & $10 / 10$ & $51 \mathrm{~W}$ \\
\hline p-t-p 1G Ethernet (8 ports) & $10 / 10$ & $40 \mathrm{~W}$ \\
\hline p-t-p 1G Ethernet (8 ports) Synch & $10 / 10$ & $43 \mathrm{~W}$ \\
\hline \hline \multicolumn{2}{|c|}{ typical power consumption breakdown } \\
\hline \hline \multicolumn{2}{|c|}{} & $13 \%$ \\
\hline - uplink & $39 \%$ \\
\hline - downlink & $37 \%$ \\
\hline - switch & $8 \%$ \\
\hline - $\mu$ P + memory & $3 \%$ \\
\hline - misc. & $15 \%$ \\
\hline AC-DC inefficiency & $35 \%$ \\
\hline additional power for cooling &
\end{tabular}

Table 1: Values of power consumption for optical network elements at network provider premisses they are directly connected and by the maximum uplink capacity of the corresponding $\mathrm{CO}$. Thus, the finite capacity of the switch between the $\mathrm{CO}$ and users sets an upper bound on the achievable data rate , $R_{U, p-t-p}^{S W}$ for $N_{S W}$ users that are connected to this switch:

$R_{U, p-t-p}^{S W}= \begin{cases}r_{D S}+r_{U S}, & \text { for } C_{S W}>N_{S W}\left(r_{U S}+r_{D S}\right) \\ C_{S W} / N_{S W}, & \text { otherwise }\end{cases}$

Here, $r_{D S}$ and $r_{U S}$ are respectively downstream and upstream data rates provided by the technology. Additionally, the limitation of the $\mathrm{CO}$ uplink can be taken into account in the following way:

$R_{U, p-t-p}^{C O}= \begin{cases}r_{D S}+r_{U S}, & \text { for } C_{C O}>N_{u s e r}\left(r_{U S}+r_{D S}\right) \\ C_{C O} / N_{u s e r}, & \text { otherwise }\end{cases}$

where, $N_{\text {user }}$ is the total number of active users connected to the $\mathrm{CO}$. The resulting achievable data rate per user is then calculated according to:

$$
R_{U, p-t-p}=\min \left(R_{U, p-t-p}^{S W}, R_{U, p-t-p}^{C O}\right) .
$$

Due to the fact that users of passive optical networks connected to the same OLT have to share both US and DS data rates, they cannot reach the maximum data rates listed in Tables 1 and 2 unless there is only one active user per OLT. While in p-t-p networks both broadcast and multicast traffic have to be multiplied and transmitted to users in parallel over different links, PONs can naturally support broadcast and multicast services by sending only a single data stream to all users. This property of PON options is addressed by introducing the broadcast factor, $B$, which represents the percentage of the downstream data rate used for broadcast services. Thus, the bidirectional data rate per user in a PON,

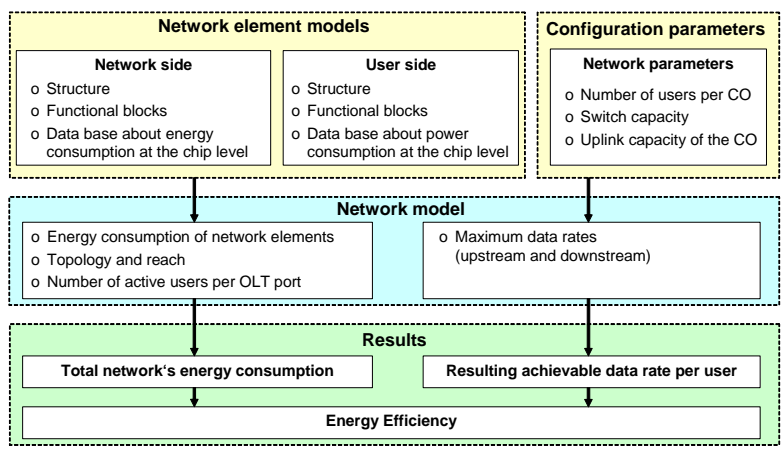

Figure 6: Depiction of the model for evaluation of energy efficiency of optical networks
Table 2: Values of power consumption for optical network elements at customer premisses 
$R_{U, P O N}$, can be calculated by considering the following three cases.

Case 1: In this case, the total bandwidth consumed by all active users is below the given limit, $C_{C O}$, which is the maximum bidirectional uplink capacity of the central office switch, i.e., when $C_{C O}>N_{O L T}\left(r_{U S}+r_{D S}\right)$, where $r_{U S}$ and $r_{D S}$ represent the maximum upstream and downstream data rates, respectively. $N_{O L T}$ is the total number of active optical line terminals in the CO. In this case, all users can be provided with the maximum data rates in both upstream and downstream directions and the total achievable data rate of a single user can be calculated using Equation (4):

$$
R_{U, P O N}^{1}=r_{D S} B+\left[r_{D S}(1-B)+r_{U S}\right] \frac{N_{O L T}}{N_{u s e r}},
$$

Case 2: The second condition reflects the case in which the bandwidth limitation is reached, but there is still no effect on the broadcast traffic, i.e., when $C_{C O} \leq$ $N_{O L T}\left(r_{U S}+r_{D S}\right)$ but $\left(C_{C O}-N_{O L T} \cdot r_{U S, L}\right) / N_{O L T}>r_{D S} \cdot B$, where $r_{U S, L}$ represents the reduced upstream data rate due to the limitation of the uplink $\left(C_{C O}\right)$. In this case, both downstream and upstream data rates are reduced, but not as much to affect delivering of broadcast services. The achievable data rate per user can be then calculated by the following formula:

$$
R_{U, P O N}^{2}=r_{D S} B+\left(r_{D S, L}-r_{D S} B+r_{U S, L}\right) \frac{N_{O L T}}{N_{u s e r}},
$$

where $r_{D S, L}$ is the reduced downstream data rate due to the limitation of the uplink.

Case 3: Finally, the third case refers to a strong reduction in the available bandwidth per user due to the uplink limitation, where not only the best-effort but also the prioritized broadcast traffic is throttled. In this case we have $C_{C O}<N_{O L T}\left(r_{U S}+r_{D S}\right)$ and $\left(C_{C O}-r_{U S, L} N_{O L T}\right) / N_{O L T}<r_{D S} B$ and the achievable data rate per user is then:

$$
R_{U, P O N}^{3}=r_{D S, L}+r_{U S, L} \frac{N_{O L T}}{N_{u s e r}}
$$

The reduced upstream and downstream data rates, $r_{U S, L}$ and $r_{U S, L}$, are given by Equations 7 - 9:

$$
\begin{aligned}
r_{D S, L} & =\frac{C_{C O}}{N_{O L T}\left(\frac{r_{U S}}{r_{D S}}+1\right)}, \\
r_{U S, L} & =\frac{C_{C O}}{N_{O L T}}-r_{D S, L},
\end{aligned}
$$

$$
\frac{C_{C O}}{N_{O L T}}=r_{D S, L}+r_{U S, L}
$$

\subsubsection{Model of cellular wireless networks}

In case of radio networks, we concentrate on energy consumption of base stations only because of the following reasons:

- system boundaries of our model are the end points of the network. We excluded end user equipment such as personal computers (PCs) and mobile user devices. Mobile user devices such as mobile phones, smartphones and tablet PCs are today primarily computational devices on which user applications are running, similar to desktop PCs and laptops.

- user mobile devices are already optimized for low energy consumption because of mobility requirements and limited size and capacity of batteries. Thus, there is a very limited room for additional improvement of energy efficiency of mobile devices.

- base stations are not yet optimized for high energy efficiency. They usually consume a lot of energy while always operated in on-state in order to provide a high-quality pilot signal.

- It has been shown recently that the energy consumption of mobile terminals is more than two orders of magnitude lower than that of base stations [23]. Consequently, the main contributor to the energy consumption is the network equipment and not the terminals.

We applied a similar approach to that used for optical network elements to model the wireless networks. We first defined generic structures of base stations [7, 8, 9]. Two examples of generic structure for macrocell and femtocell base stations are shown in Figures $7 \mathrm{a}$ and $7 \mathrm{~b}$, respectively. The values we obtained for the total energy consumption of the two base station types including typical power consumption breakdown by functional blocks are listed in Tables 3 and 4 . The cell size and supported data rate are design parameters that are calculated for each scenario and network configuration. The cell size is determined by the coverage range of a base station, $R$, which is calculated in the following manner.

A first step in determining $R$ is the calculation of the maximum allowable path loss $P L_{\max }$. The path loss is the ratio of the transmitted power to the received power of the signal. $P L_{\max }$ is then the maximum allowable path loss to which a transmitted signal can be 
subjected while still being detectable at the receiver. It includes all of the possible elements of loss that occur due to interactions between the propagating wave and obstacles in the line-of-sight between the transmitter and the receiver. Based on this $P L_{\text {max }}$, the range of a BS can be determined by using an appropriate propagation model. For the macrocell base station, the Erceg $\mathrm{C}$ model was used [26], while for the femtocell base station the model ITU-R P.1238 (residential environment) was chosen [27]. The number of macrocell and femtocell base stations needed to cover a predefined area is then determined by dividing the considered area by the coverage of the macrocell and femtocell base station. The link adaptation is not taken into account. The network is designed to provide a predefined maximum data rate over the considered area, so a fixed bandwidth, modulation and coding scheme is used. An extension of the model by including the link adaptation function will be considered in a future work.

An important parameter to define $P L_{\max }$ is the receiver SNR (Signal-to-Noise Ratio) which determines the minimum required SNR at the receiver for a certain BER (Bit Error Rate). The receiver SNR depends on the used modulation and coding rate. The modulation translates the binary bit stream into an analogue signal, while the coding rate determines the FEC (Forward Error Correction) which is responsible for the correction of errors occurred. The most important modulation schemes in wireless communication are QPSK (Quadrature Phase Shifting Keying) and 16- or 64-QAM (Quadrature Amplitude Modulation). The coding rate is typically a ratio which indicates how many redundant bits are added per number of information bit rate. The combination of modulation scheme and coding rate allows us to determine the physical bit rate which is the total number

a)

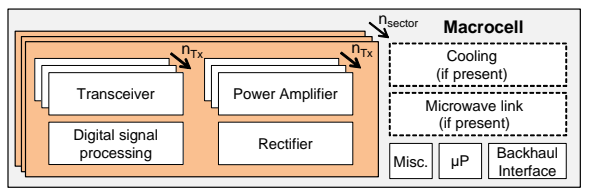

b)

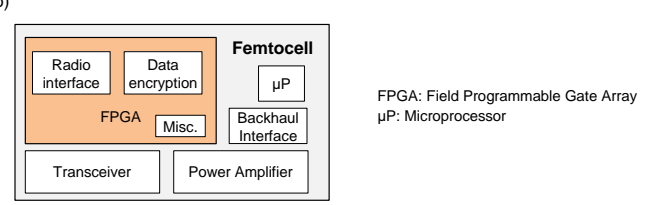

Figure 7: High-level representation of cellular wireless access network equipment: a) macrocell base station and b) femtocell base station

\begin{tabular}{|c|c|l|}
\hline network element & $\begin{array}{l}\text { max. data rate } \\
(\text { DL/UL) [Gbit/s] }\end{array}$ & power \\
\hline \hline LTE Macrocell BS (3 sectors) & $0.7 / 0.2$ & $1665.6 \mathrm{~W}$ \\
\hline \multicolumn{2}{|c|}{ typical power consumption breakdown } \\
\hline \multicolumn{2}{|c|}{ - 3 transceivers } & $28 \%$ \\
\hline - 3 power amplifiers & $43.6 \%$ \\
\hline - 3 digital signal processors & $28 \%$ \\
\hline - $\mu \mathrm{P}+$ memory & $0.2 \%$ \\
\hline - backhaul interface & $0.1 \%$ \\
\hline - misc. & $0.1 \%$ \\
\hline AC-DC inefficiency & $15 \%$ \\
\hline additional power for cooling & $35 \%$ \\
\hline
\end{tabular}

Table 3: Values of power consumption for LTE macrocell base stations

of physically transferred bits per second including useful data as well as protocol overhead. Other important parameters to determine $P L_{\max }$ are the antenna gains of both the receiver and transmitting antennas, the input power of the transmitting antenna, the used MIMO (Multiple Input Multiple Output) mode, etc. For a more detailed description of the wireless network model the reader is referred to [7].

\begin{tabular}{|c|c|c|}
\hline network element & $\begin{array}{l}\text { max. data rate } \\
(\mathrm{DL} / \mathrm{UL})[\mathrm{Gbit} / \mathrm{s}]\end{array}$ & power \\
\hline \hline LTE Femtocell BS & $0.7 / 0.2$ & $12 \mathrm{~W}$ \\
\hline \hline \multicolumn{2}{|c|}{ typical power consumption breakdown } \\
\hline \hline - transceiver & $14.4 \%$ \\
\hline - power amplifier & $19.2 \%$ \\
\hline - FPGA & $16.3 \%$ \\
\hline - $\mu \mathrm{P}+$ memory & $21.3 \%$ \\
\hline - backhaul interface & 14.4 \\
\hline - misc. & 14.4 \\
\hline AC-DC inefficiency & $15 \%$ \\
\hline
\end{tabular}

Table 4: Values of power consumption for LTE femtocell base stations

\section{Considered Scenarios}

This section describes the assumptions made and the scenarios considered in this study. Several deployment scenarios are defined for a fixed number of inhabitants and different population densities. We assume 
here 1 Million inhabitants and vary the population density within a certain area between three values, namely $p_{d 1}=4,000, p_{d 2}=1,000$ and $p_{d 3}=100$ people per square kilometer, which we in the residual part of the present paper refer to as urban, suburban and rural areas. Thus, we can now calculate three areas to be covered by the combined wireless/optical network for three population densities, i.e., $A_{1}=250 \mathrm{~km}^{2} A_{2}=1,000 \mathrm{~km}^{2}$ and $A_{3}=10,000 \mathrm{~km}^{2}$, respectively.

Activity of network users is considered through defining the activity factor, $f_{a}$, which shows how many users are active in average at each particular point of time of the day. The activity factors are based on statistical data and measurements [28, 29, 30] and follow a sinusoidal-like curve with a maximum in the afternoon hours between $6 \mathrm{pm}$ and $9 \mathrm{pm}$ and a minimum in the early morning hours as shown in Figure 9 . In order to take into account future changes of user behavior and developments in network technologies, we assume here three activity factors and four average data rates. The three activity factors are obtained by defining the basis activity factor and multiplying it by a factor of two and four as shown in Figure 9. The average access data rates that we assume for users of wireless and wired networks are shown in Table 5. $\mathrm{DR}_{1}$ represents the average data rate per active user in current access networks [30, 31], while $\mathrm{DR}_{2}, \mathrm{DR}_{3}$ and $\mathrm{DR}_{4}$ are projected data rates for the years 2014, 2016 and 2020 [31]. The ratio between downstream/upstream data rates is set to $3 / 2$. The penetration of RF cellular access is assumed to be $90 \%$ and that of wired access 28\% [32]. The considered input parameters are summarized in Tables 5 and 6

Since we are interested in energy efficiency of different LTE femtocell deployment scenarios, we change the area covered by femtocells from $0 \%$ to $80 \%$. The deployed femtocells are assumed to be almost uniformly distributed over the covered area, which can be the case

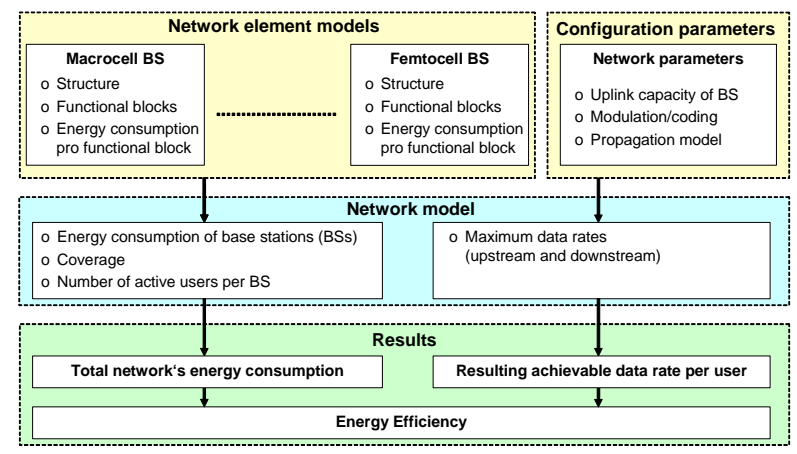

Figure 8: Depiction of the model for evaluation of energy efficiency of wireless cellular networks

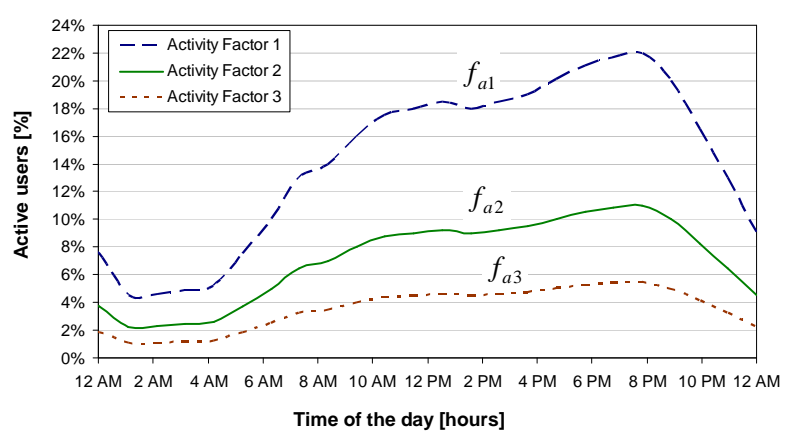

Figure 9: Considered day/night profiles of user activity (activity factors).

\begin{tabular}{|l||l|l|l|l|}
\hline \multicolumn{1}{|c||}{} & \multicolumn{2}{c|}{ wireless access } & \multicolumn{2}{c|}{ wired access } \\
\hline & $\begin{array}{l}\text { US } \\
{[\text { Mbit/s] }}\end{array}$ & $\begin{array}{l}\text { DS } \\
{[\text { Mbit/s }]}\end{array}$ & $\begin{array}{l}\text { US } \\
{[\text { Mbit/s] }]}\end{array}$ & $\begin{array}{l}\text { DS } \\
{[\text { Mbit/s }]}\end{array}$ \\
\hline \hline $\mathrm{DR}_{1}$ (current) & 0.189 & 0.126 & 0.80 & 0.34 \\
\hline $\mathrm{DR}_{2}(2014)$ & 0.742 & 0.494 & 1.80 & 1.20 \\
\hline $\mathrm{DR}_{3}(2016)$ & 1.724 & 1.149 & 9.00 & 6.00 \\
\hline $\mathrm{DR}_{4}(2020)$ & 6.780 & 4.520 & 600.00 & 400.00 \\
\hline
\end{tabular}

Table 5: Considered average upstream (US) and downstream (DS) data rates per active user.

in residential areas with quasi-uniform building density.

Perhaps the most probable case is to deploy femtocells in addition to an existing macrocell-based network in order to provide higher data rates to users. We compare this case with a pure macrocell-based network and with a network based on femtocells only, where existing macrocells and microcells are completely replaced by femtocells. In the scenarios with macrocells, the macrocell coverage is assumed to be $98 \%$.

\section{Results and Discussions}

The obtained results for the three areas and various femtocell deployment scenarios are presented in Figures $10-15$.

\subsection{Femtocell deployment in suburban areas}

Figure 10a shows the total energy consumed by the wireless cellular network with an optical backhaul based on GPON within a suburban area covering 1,000 $\mathrm{km}^{2}$. Besides the parameters listed in Tables 5 and 6 , we assumed here an average area of macrocells of 1.87 $\mathrm{km}^{2}$ and a guaranteed data rate of $8.5 \mathrm{Mbit} / \mathrm{s}$ and thus, the number of macrocell base stations (BS) needed for achieving a coverage of $98 \%$ is 526 . Both macro and 
a)

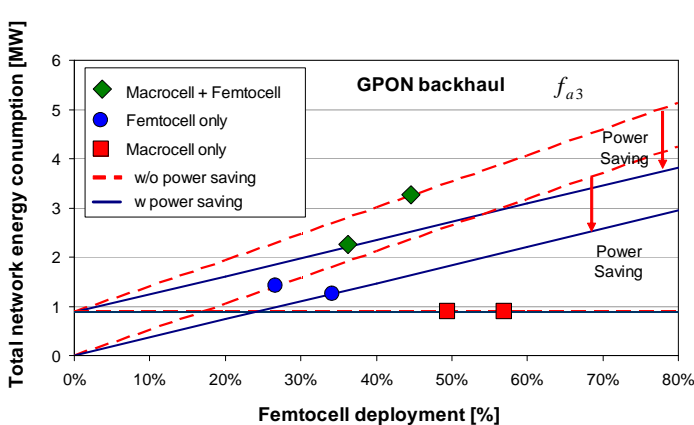

b)

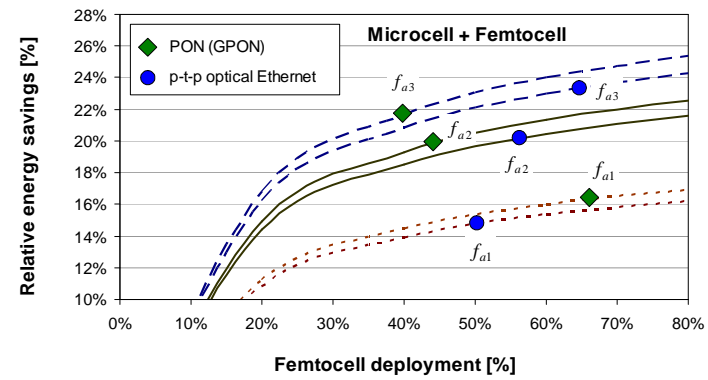

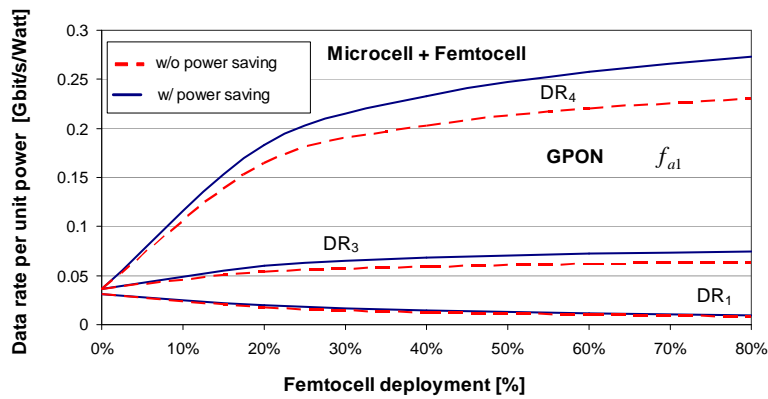

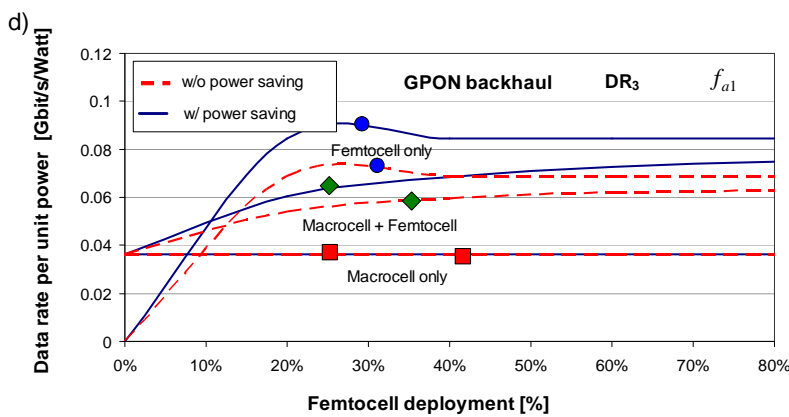

Figure 10: Energy efficiency of femtocell deployment with an optical backhaul in suburban area: a) total network energy consumption and possible energy savings when using low-power modes, b) relative energy savings with p-t-p and p-t-mp (PON) optical backhaul and for three different user activity factors $\left(f_{a 1}, f_{a 2}\right.$, and $\left.\left.f_{a 3},\right), \mathrm{c}\right)$ energy efficiency of coexisting macrocell and femtocell networks for three different average access data rates $\left(\mathrm{DR}_{1}, \mathrm{DR}_{2}\right.$, and $\left.\mathrm{DR}_{3}\right)$, and $\mathrm{d}$ ) energy efficiency of future optically backhauled LTE networks employing either macrocell or femtocell or a combination of mactrocell and femtocell base stations.

a)

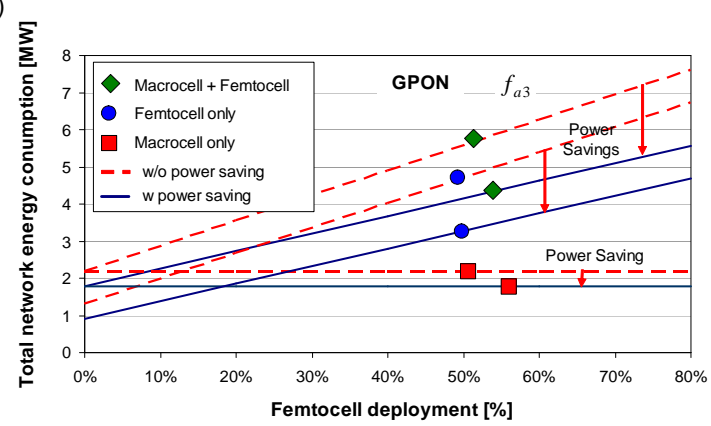

b)

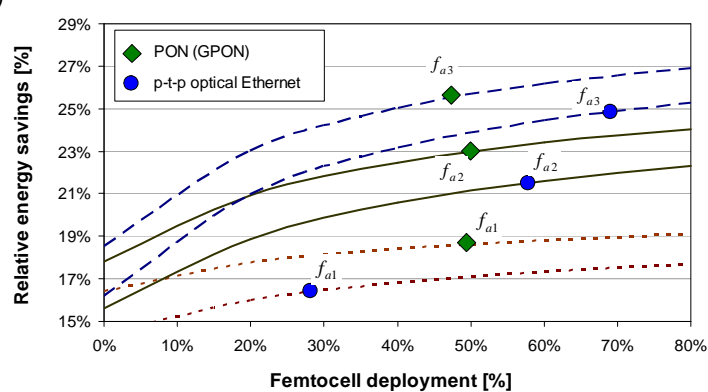

c)
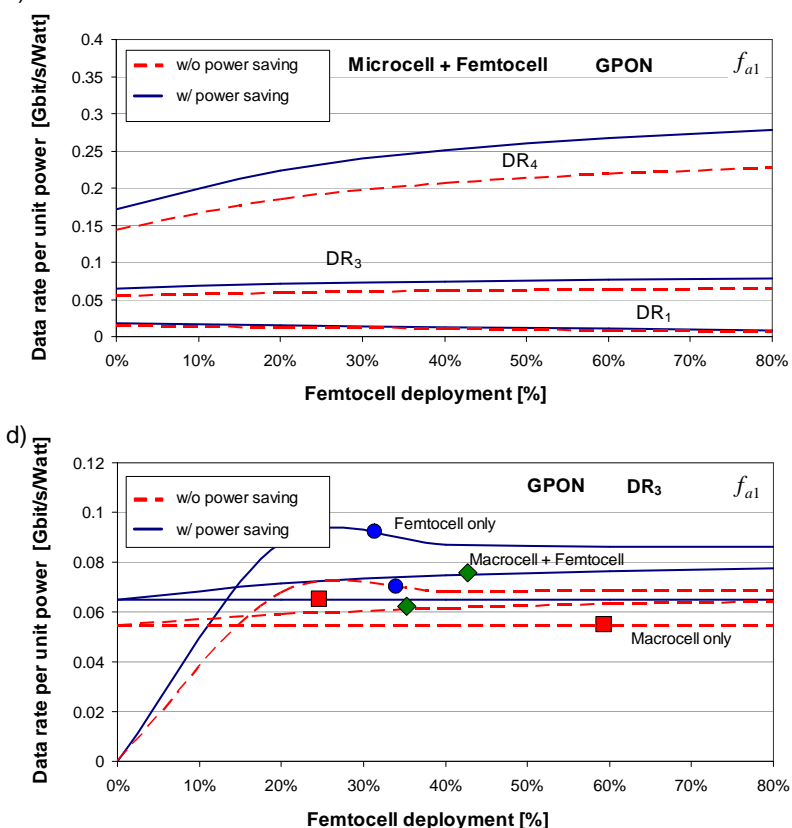

Figure 11: Energy efficiency of femtocell deployment with an optical backhaul and a coexisting optical access network in suburban area: a) total network energy consumption and possible energy savings when using low-power modes, b) relative energy savings with p-t-p and p-t-mp (PON) optical backhaul and for three different user activity factors $\left(f_{a 1}, f_{a 2}\right.$, and $\left.f_{a 3},\right)$, c) energy efficiency of coexisting macrocell and femtocell networks for three different average access data rates $\left(\mathrm{DR}_{1}, \mathrm{DR}_{2}\right.$, and $\left.\mathrm{DR}_{3}\right)$, and d) energy efficiency of future optically backhauled LTE networks employing either macrocell or femtocell or a combination of mactrocell and femtocell base stations. 


\begin{tabular}{|l||l|l|l|}
\hline \multicolumn{1}{|c||}{} & \multicolumn{2}{c|}{ 1 Million inhabitants } \\
\hline \hline population density & $\begin{array}{l}4,000 \\
\text { (urban) }\end{array}$ & $\begin{array}{l}1,000 \\
\text { (suburban) }\end{array}$ & $\begin{array}{l}100 \\
\text { (rural) }\end{array}$ \\
\hline covered area $\left[\mathrm{km}^{2}\right]$ & 250 & 1,000 & 10,000 \\
\hline DS/US ratio & \multicolumn{3}{|c|}{$3 / 2$} \\
\hline penetration wireless & \multicolumn{3}{||}{$90 \%$} \\
\hline penetration wired & \multicolumn{3}{|c|}{$28 \%$} \\
\hline coverage macro & \multicolumn{3}{|c|}{$58 \%$} \\
\hline bandwidth macro & \multicolumn{3}{|c|}{$1 / 2$} \\
\hline coding rate macro & \multicolumn{3}{|c|}{$0 \%-80 \%$} \\
\hline coverage femto & \multicolumn{3}{|c|}{$5 \mathrm{MHz}$} \\
\hline bandwidth femto & \multicolumn{3}{|c|}{$2 / 3$} \\
\hline coding rate femto & \multicolumn{3}{|c|}{} \\
\hline
\end{tabular}

Table 6: Considered parameters for femtocell deployments in urban, suburban and rural areas.

femto base stations use the 16-QAM modulation format. Additionally, we assumed for femtocell base stations that there is no more than one active user within a femtocell at a time.

The energy consumption is ploted versus the percentage of the area covered by femtocells for the three network realizations using either macrocells only or macrocells and femtocells or femtocells only.

As can be seen from Figure 10a, a deployment of femtocells additionally to the existing macrocell based network leads to an increased total network energy consumption. If we would implement a pure femtocell network in suburban area, it would consume the same energy for a coverage of approximately $17 \%$ as a network based on macrocells only with a coverage of $98 \%$. However, femtocells are able to provide a higher data rate per user, which can lead to a lower energy consumed to transmit a certain amount of data. Thus, femtocell networks, if highly utilized, can achieve a high energy efficiency measured in Gbit/s per Watt as it is evident from Figure 10d.

An additional benefit of using femtocells is that various power saving methods can be more easily and more effectively applied. In this study, we assume the use of the idle mode procedure based on noise rise as described in [33] for femtocells and shedding of optical network terminals (ONTs) for optical access networks as defined in [34]. In both cases the connection to the network is retained in order to avoid time-consuming boot-up times and the need for re-synchronization. When applying these methods, the power consumption of a femtocell base station can be reduced from 12 Watt when active to
7.8 Watt in the idle mode while, e.g., a GPON ONT consumes about 2.6 Watt with power shedding in comparison to 4.2 Watt in the active mode. In case of femtocell base stations, the power savings are achieved by switching off the power amplifier, RF transceiver, and miscellaneous hardware components that implement various nonessential functionalities for the idle mode such as data encryption and hardware authentication. However, a low-power radio sniffer that consumes $0.3 \mathrm{~W}$ has to be switched on in order to detect an active call from a mobile device to the underlying macrocell [33]. On the other hand, the power shedding techniques allows large savings in the optical access network terminals through switching off the user interface (Eth. PHY and Eth. MAC) and putting the ONT (ONU) SoC in low activity mode [34].

Utilization of the power saving techniques can indeed help in reducing the total energy consumption as shown in Figure 10a. In suburban areas, the achievable reduction of energy consumption is between $16 \%$ and $27 \%$. Figure 10b shows the relative savings for the three considered user activity profiles as presented in Figure 9. The relative energy savins are calculated using the following formula: $\left(E_{\text {save }}-E_{\text {tot }}\right) / E_{\text {tot }}$, where $E_{\text {tot }}$ and $E_{\text {save }}$ denote the total network energy consumption and the amount of energy that can be saved by utilizing the lowpower modes, respectively. If users become more active, a lower number of femtocell base stations can be put in the idle mode, and thus, less energy can be saved. For instance, relative power savings of more than $25 \%$ are possible for $80 \%$ femtocell coverage when considering the user activity corresponding to the profile $f_{a 3}$. When more users are concurrently active, which is the case for $f_{a 1}$, the maximum achievable reduction of energy consumption in comparison to the case without using low-power modes becomes less than $17 \%$. If the p-t-p optical backhaul is used instead of a PON based one, the achievable relative savings can be further reduced by approximately $2 \%$.

Figures $10 \mathrm{c}$ and $10 \mathrm{~d}$ take into consideration additionally to energy consumption also the achievable data rate per user. Here, energy efficiency of different wireless network deployment scenarios is presented in Gbit/s/Watt. For high average access data rates the energy efficiency increases with increasing the femtocell coverage. Thus, although adding femtocell base statoins to the network leads to a higher total energy consumption, the advantage of providing higher data rates results in a lower energy needed to transmit a certain amount of data. However, if the high data rate per user that can be provided by femtocell base stations is not used, which is the case for the relatively low average 
access data rate $\mathrm{DR}_{1}$, energy efficiency decreases with increasing the femtocell coverage. The highest energy efficiency and the largest relative energy savings can be achieved in a pure femtocell network because high data rates per user are possible and a large number of base stations can be put in the idle mode (see Figure 10d).

Energy efficiency of the combined optical wired and cellular wireless access network is shown in Figure 11. The same optical access technology (GPON) is assumed for both the fixed access and the backhaul of the mobile network. The combined wired/wireless access network consumes more energy than the optically backhauled wireless network (see Figures 11a and 10a), but it is also able to serve more users concurrently with higher data rates. For example, a network providing $98 \%$ coverage with macrocells and $80 \%$ coverage by femtocells together with an optical wired access based on GPON with a penetration of $28 \%$ consumes slightly less than $8 \mathrm{MW}$ (Figure 11a) in comparison to $5.2 \mathrm{MW}$ in case of the wireless network with optical backhoul only (see Figure 10a). However, due to the presence of the wired optical access network, the achievable average data rates are high even for the case with less deployed femtocell base stations (Figures 11c and 11d), which leads to an initial high energy efficiency and large relative power savings at high average access rates. Also the difference between $\mathrm{p}-\mathrm{t}-\mathrm{mp}(\mathrm{PON})$ and $\mathrm{p}$ - $\mathrm{t}-\mathrm{p}$ optical access becomes more evident (Figure 11b).

\subsection{Femtocell deployment in urban areas}

For urban areas of $250 \mathrm{~km}^{2}$, we calculated the required number of macrocell base stations to be 629 with an average cell area of $0.39 \mathrm{~km}^{2}$ and a guaranteed data rate of $8.5 \mathrm{Mbit} / \mathrm{s}$. In this case, QPSK was assumed for macro and 16-QAM for femto base stations. All other configuration parameters are reported in Table 5.

In urban areas, a high coverage can be achieved by deploying less base stations. Thus, the total energy consumption of the optically backhauled LTE network in urban area is significantly lower than that of a suburban network as it can be seen when comparing Figures 12a and 10a. Concurrently, a lower number of femtocell base stations can be put into the idle mode because of the high population density, so the chance there is an active user within a femtocell increases. Therefore, the relative energy savings are not as high as in the suburban area (see Figures 12b and 10b), but the amount of transmitted data per unit energy is for a factor of 2 to 3 larger (Figures 12c and 12d in comparison to Figures $10 \mathrm{c}$ and $10 \mathrm{~d})$.

Similar conclusions can be drown when observing Figure 13 that shows results for energy efficiency of a combined optical wired and cellular wireless network in urban areas. The only difference to the backhaul only case is that when optical wired access is added the relative power savings become larger. Although high energy savings are possible in the urban area, the relative savings decrease with increase in femtocell coverage in case of high user activity, i.e., for user activity profiles $f_{a 1}$ and $f_{a 2}$, which is evident from Figure 13b. This is because as more femtocell base stations are installed, the total energy consumption increases, while the benefit of using low-power modes decreases due to the increased user activity and longer periods in which femtocell base stations have to be in the active state.

\subsection{Femtocell deployment in rural areas}

In a rural area of $10,000 \mathrm{~km}^{2}$, the calculated number of macrocell base stations is 1,816 with an average cell area of $5.4 \mathrm{~km}^{2}$ and a guaranteed data rate of 2.8 Mbit/s. Similar to the suburban case, we also assumed here QPSK for macro and 16-QAM for femto base stations.

As one could intuitively expect, a combined opti$\mathrm{cal} /$ wireless access network seems not to be an adequate option for rural areas due to the very low population density. As it becomes evident from Figures 14 and 15, a roll out of an optical access network to serve as backhaul for a femtocell based LTE network would lead to a very high energy consumption and a low energy efficiency, especially for a large femtocell coverage and low average access data rates. A network in a rural area with $98 \%$ macrocell coverage, $80 \%$ femtocell coverage, and $28 \%$ GPON penetration would consume about $60 \mathrm{MW}$ of power (see Figure a), which is 15 times more energy than needed for powering the network in an urban area (Figure 13). Furthermore, the energy efficiency measured in Gbit/sec/Watt is for a factor of 5 to 15 lower in a rural area than in an urban area (Figures $15 \mathrm{~d}$ and 13d). An interesting effect of decreasing energy efficiency with increasing femtocell coverage can be observed in case of coexistence of macrocell and femtocell base stations in rural areas (Figures $14 \mathrm{~d}$ and 15d). This is because in rural areas the energy consumption increases faster than the achievable average access data rate when increasing the number of femtocell base stations. Hence, even for very high average access rates the combined optical wired and cellular wireless network provides low energy efficiency in rural areas. Consequently, the deployment scenarios for femtocells in rural areas do not bring any advantage regarding both the total energy consumption and the achievable data rate per unit power. 
a)
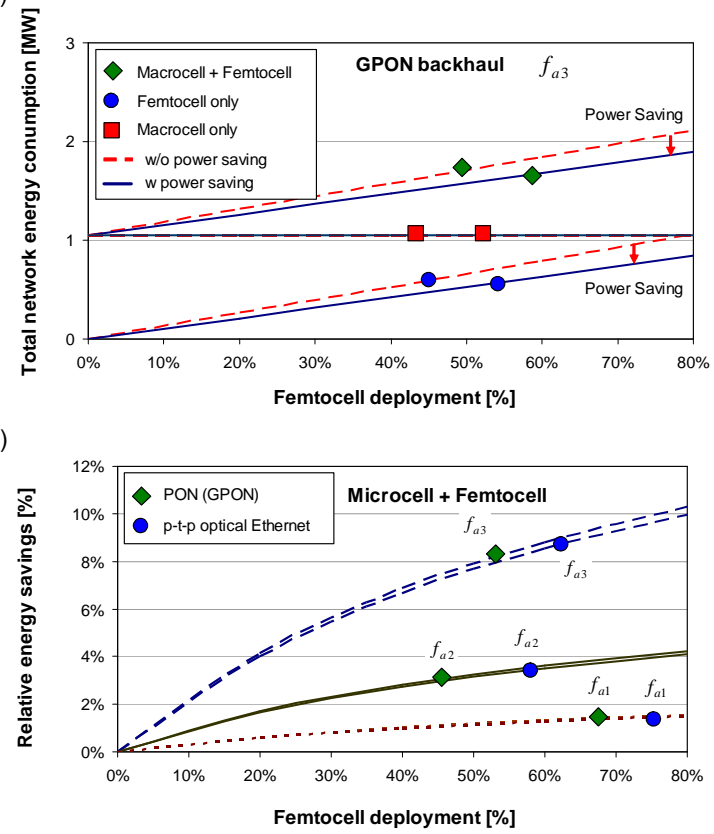

c)
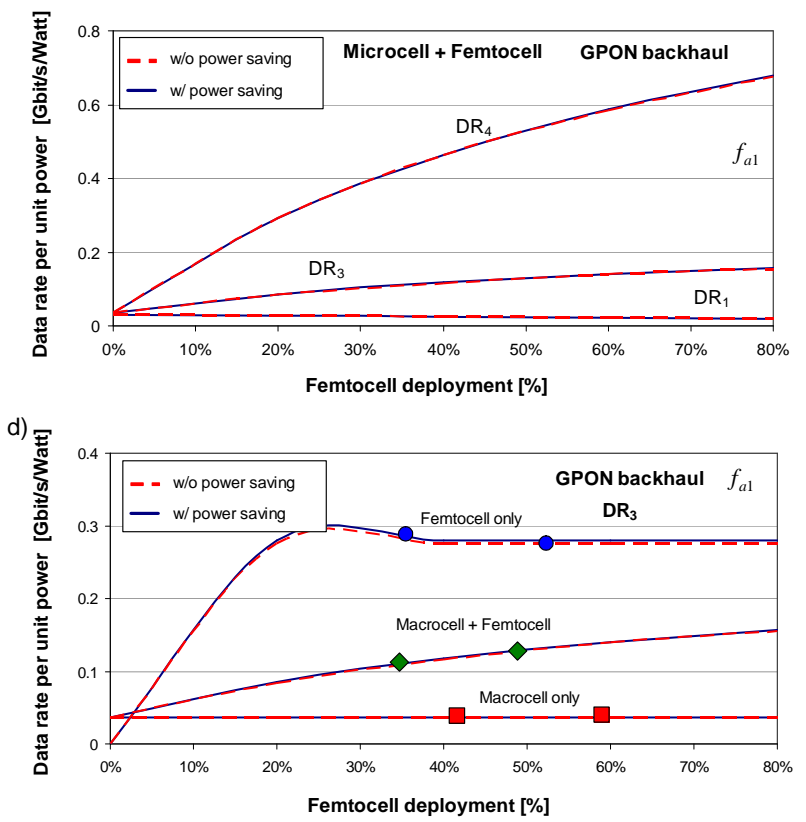

Figure 12: Energy efficiency of femtocell deployment with an optical backhaul in urban area: a) total network energy consumption and possible energy savings when using low-power modes, b) relative energy savings with p-t-p and p-t-mp (PON) optical backhaul and for three different user activity factors $\left(f_{a 1}, f_{a 2}\right.$, and $\left.f_{a 3},\right)$, c) energy efficiency of coexisting macrocell and femtocell networks for three different average access data rates $\left(\mathrm{DR}_{1}, \mathrm{DR}_{2}\right.$, and $\left.\mathrm{DR}_{3}\right)$, and d) energy efficiency of future optically backhauled LTE networks employing either macrocell or femtocell or a combination of mactrocell and femtocell base stations.

a)

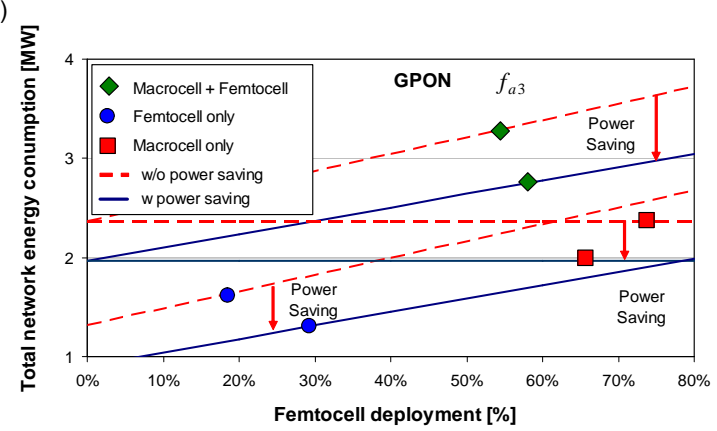

b)

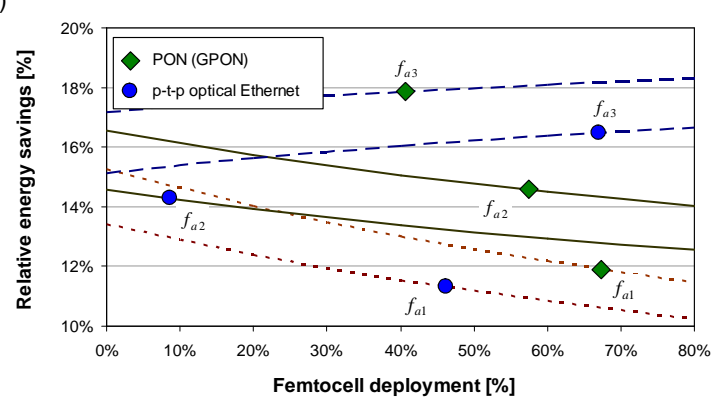

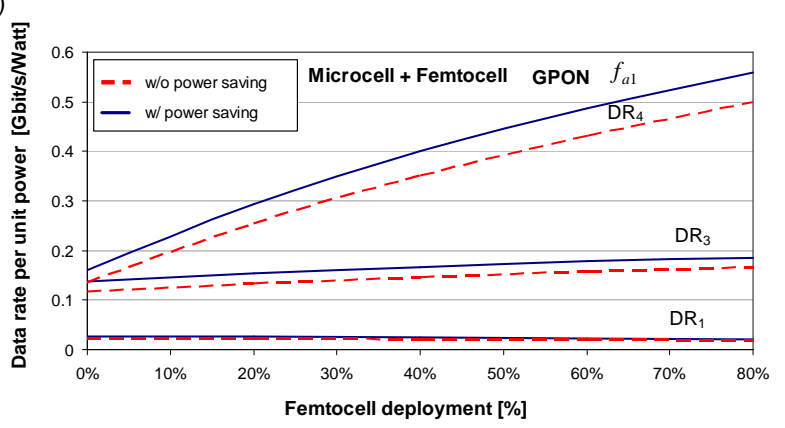

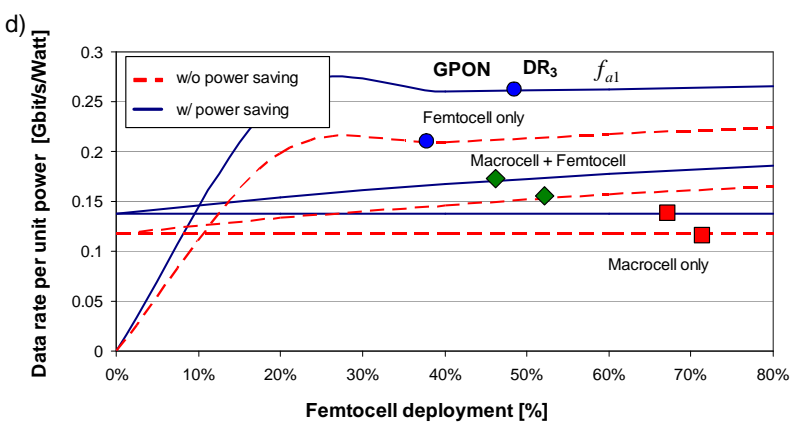

Figure 13: Energy efficiency of femtocell deployment with an optical backhaul and a coexisting optical access network in urban area: a) total network energy consumption and possible energy savings when using low-power modes, b) relative energy savings with p-t-p and p-t-mp (PON) optical backhaul and for three different user activity factors $\left(f_{a 1}, f_{a 2}\right.$, and $\left.f_{a 3},\right)$, c) energy efficiency of coexisting macrocell and femtocell networks for three different average access data rates $\left(\mathrm{DR}_{1}, \mathrm{DR}_{2}\right.$, and $\left.\mathrm{DR}_{3}\right)$, and d) energy efficiency of future optically backhauled LTE networks employing either macrocell or femtocell or a combination of mactrocell and femtocell base stations. 


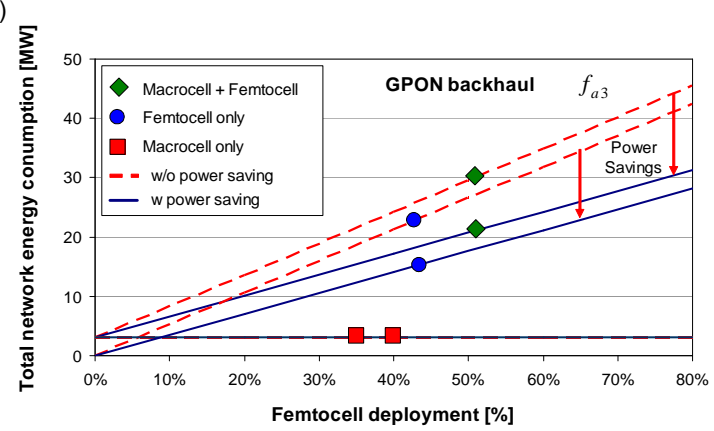

b)

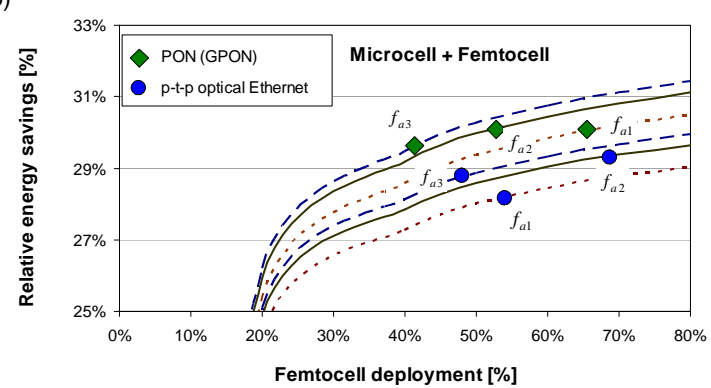

c)
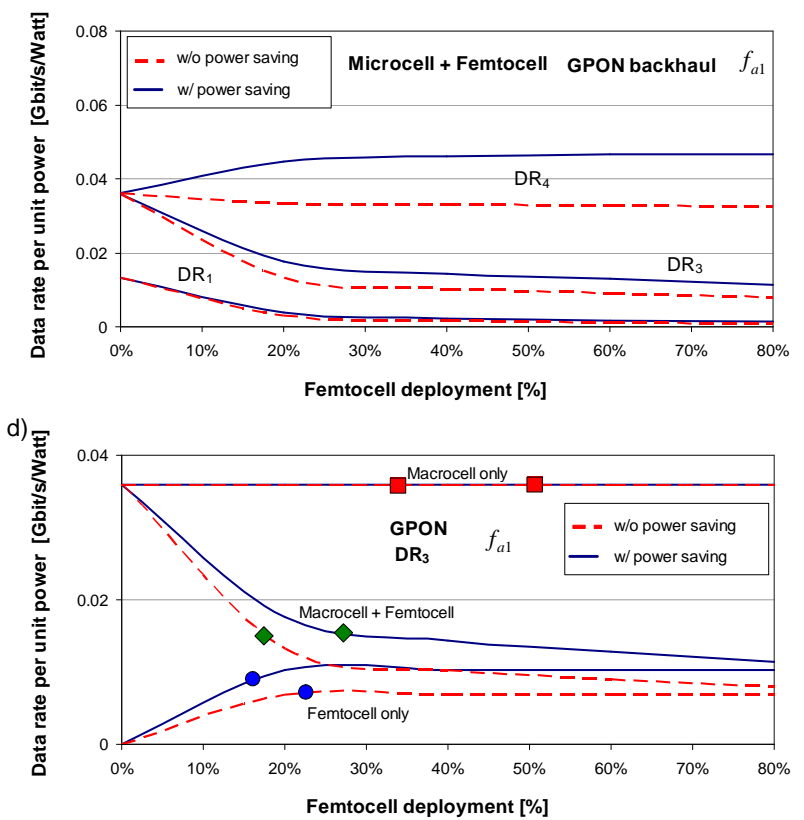

Figure 14: Energy efficiency of femtocell deployment with an optical backhaul in rural area: a) total network energy consumption and possible energy savings when using low-power modes, b) relative energy savings with p-t-p and p-t-mp (PON) optical backhaul and for three different user activity factors $\left(f_{a 1}, f_{a 2}\right.$, and $\left.f_{a 3},\right), \mathrm{c}$ ) energy efficiency of coexisting macrocell and femtocell networks for three different average access data rates $\left(\mathrm{DR}_{1}, \mathrm{DR}_{2}\right.$, and $\left.\mathrm{DR}_{3}\right)$, and d) energy efficiency of future optically backhauled LTE networks employing either macrocell or femtocell or a combination of mactrocell and femtocell base stations.

a)

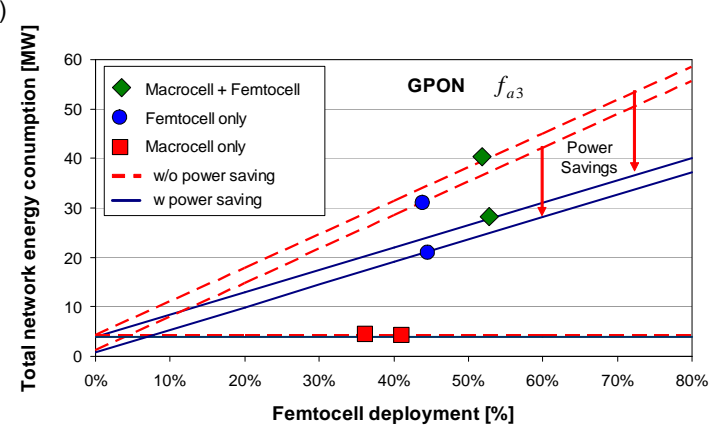

b)

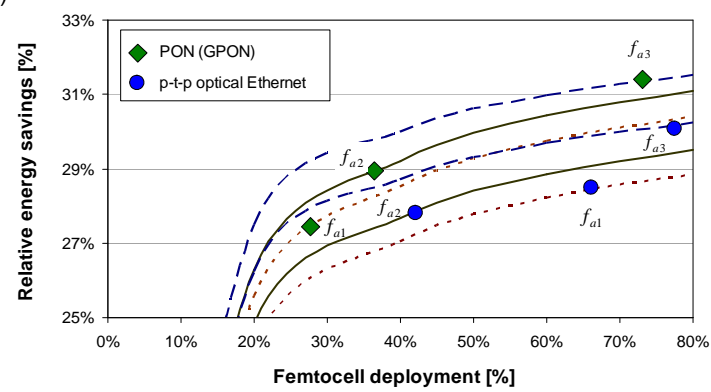

c)
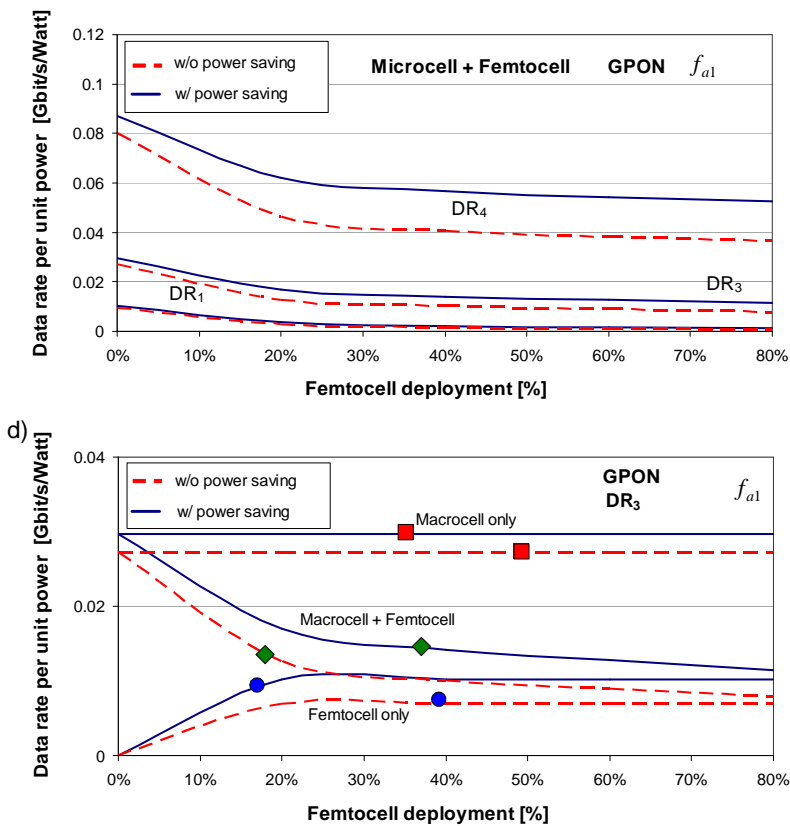

Figure 15: Energy efficiency of femtocell deployment with an optical backhaul and a coexisting optical access network in rural area: a) total network energy consumption and possible energy savings when using low-power modes, b) relative energy savings with p-t-p and p-t-mp (PON) optical backhaul and for three different user activity factors $\left(f_{a 1}, f_{a 2}\right.$, and $\left.\left.f_{a 3},\right), \mathrm{c}\right)$ energy efficiency of coexisting macrocell and femtocell networks for three different average access data rates $\left(\mathrm{DR}_{1}, \mathrm{DR}_{2}\right.$, and $\left.\mathrm{DR}_{3}\right)$, and d) energy efficiency of future optically backhauled LTE networks employing either macrocell or femtocell or a combination of mactrocell and femtocell base stations. 


\section{Summary and Conclusions}

In conclusion, we presented a novel model for evaluating the energy efficiency of converged wireless/optical access networks. The model takes into account the main architectural and implementational aspects of both wireless and optical parts of the network. Several deployment scenarios for combined wireless/optical networks were defined and possible deployments of femtocell base stations analyzed by means of achievable energy efficiency. We also analyzed possible energy savings by utilizing practically applicable methods that are based on low-power modes for both femtocell base stations and optical network terminals.

Energy efficiency of a deployment of femtocell base stations strongly depends on the population density, average access data rates, and the number of concurrently active users in a certain area to be covered. We concentrated on an implementation basing on the LTE technology for the wireless part and the point-to-point optical Ethernet or passive optical networks (Ethernet-based EPON and ATM-based GPON) for the optical wired access and wireless backhaul. In general, the combined wireless/optical access network has the potential to increase the overall energy efficiency of the access area, especially when assuming future high average access data rates. In this context, passive optical access networks (PON) are better suited to serve as backaul to the LTE network. If the femtocell base stations are installed in addition to an existing macrocell-based network, the overall power consumption of the combined network increases with the increase in femtocell coverage. However, in urban and suburban areas, the introduction of femtocells usually leads to an increased energy efficiency measured as the amount of data that can be transmitted per unit energy, i.e., in bit/second/Watt $\equiv$ bit/Joule. In rural area, the very high energy consumption of a combined femtocell and macrocell network leads to a decrease in efficiency in comparison to pure macrocell network. For example, in urban and suburban areas, relative energy savings of about $10 \%$ to $27 \%$ and efficiencies on the order of hundreds of Mbit/s/W are achievable when utilizing low-power modes. Although in rural areas the use of low-power modes can lead to high energy savings of up to $30 \%$, the total energy consumption increases by a factor of 15 and the energy efficiency is by 5 to 15 times lower than in the urban area, which makes femtocells less attractive for rural areas from the energy efficiency perspective.

Thus, the findings of this study can be summarized as follows. Although deployment of femtocells does not necessarily lead to a lower total network power con- sumption, it can certainly result in a significant increase of both access data rates and energy efficiency in areas with high population densities such as in city centers or within business parks and shopping centers. The energy efficiency can be further increased by utilizing effective power saving mechanisms and using passive optical networks as wireless backhaul. Another important precondition for fully exploiting the potential of femtocells is a broad availability and an extensive use of bandwidthintensive applications and services. According to our results and taking into account current prognoses for the future growth of access data rates, a remarkable improvement of energy efficiency due to a wide deployment of femto base stations can not be expected before 2016.

\section{Acknowledgments}

The work described in this paper was supported in part by the project HOME-ICT funded by the Austrian Fund for Climate and Energy and accomplished within the framework of the program "NEUE ENERGIEN $2020 "$.

\section{References}

[1] ITU-T Statistics 2011, http : //www.itu.int/ITU D/ict/statistics/index.html.

[2] S. Aleksic, "Energy Efficiency of Electronic and Optical Network Elements" (invited), IEEE Journal on Selected Topics in Quantum lectronics, Vol. 17, No. 2, March/April 2011, pp. 269-308.

[3] C. Lange, D. Kosiankowski, C. Gerlach, F. J. Westphal, A. Gladisch, "Energy Consumption of Telecommunication Networks", 35th European Conference on Optical Communications (ECOC 2009), Vienna, Austria, Sept. 20- 24, 2009, paper 5.5.3.

[4] S. Aleksic, "Energy-Efficient Communication Networks for Improved Global Energy Productivity", in Telecommunication Systems, Springer, scheduled for publication in 2012.

[5] S. Aleksic, A. Lovric, "Energy Consumption and Environmental Implications of Wired Access Networks", in American Journal of Engineering and Applied Sciences, Science Publications, Vol. 4 (2012), No. 4; pp. 531 - 539.

[6] W. Vereecken, W. Van Heddeghem M. Deruyck, B. Puype, B. Lannoo, W. Joseph, D. Colle, L. Martens, and P. Demeester, "Power consumption in telecommunication networks: overview and reduction strategies", IEEE Communication Magazine, Vol. 49, No. 6, June 2011, pp. 6269.

[7] M. Deruyck, E. Tanghe, W. Joseph, L. Martens, "Modelling and Optimization of Power Consumption in Wireless Access Networks", Elsevier Computer Communications, Vol. 34, No. 17, November 2011, pp. 2036-2046.

[8] M. Deruyck, E. Tanghe, W. Joseph, L. Martens, "Modelling the Energy Efficiency of Microcell Base Stations", First International Conference on Smart Grids, Green Communications and IT Energy-Aware Technologies (ENERGY), Venice, Italy, May 2011, pp. 1-6. 
[9] M. Deruyck, D. De Vulder, W. Joseph, L. Martens, "Modelling the Power Consumption in Femtocell Networks", IEEE Wireless Communications and Networking Conference (WCNC): Workshop on Future Green Communications, April 2011, pp. 30-35.

[10] W. Vereecken, M. Deruyck, D. Colle, W. Joseph, M. Pickavet, L. Martens, P. Demeester, "Evaluation of the Potential for Energy Saving in Macrocell and Femtocell Networks using Heuristic Introducing Sleep Modes in Base Stations", EURASIP Journal on Wireless Communications and Networking - special issue: Green Radio, Vol. 2012, No. 1, 2012, doi:10.1186/1687-14992012-170.

[11] M. Deruyck, E. Tanghe, W. Joseph, L. Martens, "Characterization and Optimisation of the Power Consumption in Wireless Access Networks by Taking Daily Traffic Variations into account", Eurasip Journal on Wireless Communications and Networking - special issue: Recent Advances in Optimization Techniques in Wireless Communication Networks, doi:10.1186/1687-14992012-248.

[12] Z. Hasan, H. Boostanimehr, and V. K. Bhargava,'Green Cellular Networks: A Survey, Some Research Issues and Challenges", IEEE Communications Surveys \& Tutorials, Vol. 13, No. 4, Sept. 2011, pp. 524-540.

[13] E. Oh, B. Krishnamachari, "Energy Savings through Dynamic Base Station Switching in Cellular Wireless Access Networks", IEEE Global Telecommunications Conference (GLOBECOM 2010), Miami, FL, USA, Dec. 2010, pp. 1-5.

[14] A. R. Dhaini, P.-H. Ho, and G. Shen, "Toward Green NextGeneration Passive Optical Networks", IEEE Communications Magazine, Vol. 49, No. 11, November 2011, pp 94-101, 2011.

[15] 3GPP, "LTE: 3rd Generation Partnership Project: Technical Specification Group Radio Access Network: Evolved Universal Terrestrial Radio Access (E-UTRA): User Equipment (UE) radio transmission and reception (TS 36.101 v9.1.0 Release 9", September 2009

[16] TeliaSonera, "Pioneering 4G", available at http : //www.teliasonera.com/en/innovation/access - is king/2011/4/pioneering - 4g - networks/, accessed March 2012.

[17] I. F. Akyildiz, D. M. Gutierrez-Estevez, E. C. Reyes, "The evolution to 4G cellular systems: LTE-Advanced", Elesevier Physical Communication, Vol. 3, No. 4, 2010, pp. 217-244, DOI: 10.1016/j.phycom.2010.08.001

[18] RVA Market Research \& Consulting, "North American FTTH Status, March 2011, FTTH Council, 2011, http : //www.fthcouncil.org/K. $-I$.

[19] Suzuki, "Long Reach PON System Using Optical Fiber Amplifier,' in Proceedings of OFC/NFOEC 2008, San Diego, CA, USA, workshop, February 2008

[20] IDATE Consulting and Research, "FTTx 2010, Markets \& Trends, Facts \& Figures" 2010, http : //www.idate.org

[21] G. Shen, R. S. Tucker, and T. Chae, "Fixed Mobile Convergence (FMC) Architectures for Broadband Access: Integration of EPON and WiMAX", IEEE Communications Magazine, August 2007, pp. 44-50.

[22] D. Wake, "Radio over Fiber Systems for Mobile Applications", in "Radio over Fiber Technologies for Mobile Communications Networks", H. Al-Raweshidy, and S. Komaki, ed. (Artech House, Inc, USA), 2002.

[23] M. Etoh, T. Ohya, and Y. Nakayama, "Energy Consumption Issues on Mobile Network Systems," International Symposium on Applications and the Internet (SAINT 2008), pp. 365-368, 2008.

[24] S. Aleksic, A. Lovric: "Power Efficiency in Wired Access Networks"; Elektrotechnik und Informationstechnik (e\&i), Vol. 127 No. 11, 2010, pp. 321-326.

[25] A. Lovric and S. Aleksic, "Power Efficiency of Extended Reach
10G-EPON and TDM/WDM PON", in Proceedings of National Fiber Optic Engineers Conference (NFOEC 2010), San Diego, CA, USA, March 2010, paper NMC4.

[26] V. Erceg, L. J. Greenstein, S. Y. Tjandra, S. R. Parkoff, A. Gupta, B. Kulic, A. A. Julius, R. Bianchi, "An Empirically Based Path Loss Model for Wireless Channels in Suburban Environments", IEEE Journal on Selected Areas in Communications, Vol. 17, No. 7, 1999, pp. 1205-1211.

[27] Recommendation ITU-R P.1238-2, "Propagation data and prediction methods for the planning of indoor radiocommunication systems and radio local area networks in the frequency range $900 \mathrm{MHz}$ to $100 \mathrm{GHz}, 1997-1999-2001$.

[28] Byte Mobile "Mobile Analytics Report", June 2011, pp. 1-12, online available under: http : //www.bytemobile.com/news events/mobile nalytics $_{r}$ eport.html.

[29] O. Eunsung, B. Krishnamachari, "Energy Savings through Dynamic Base Station Switching in Cellular Wireless Access Networks", IEEE Global Telecommunications Conference (GLOBECOM 2010), Miami, Florida, USA December 2010, pp. 1-5.

[30] M. Kihl, A. Aurelius, C. Lagerstedt, P. Ödling, "Traffic analysis and characterization of Internet user behavior", International Congress on Ultra Modern Telecommunications and Control Systems (ICUMT 2010), Moscow, Russia, October 2010, pp. 224231.

[31] Cisco, "Cisco Visual Networking Index: Global Mobile Data Traffic Forecast Update, 20112016”, White paper, February 2012, pp. 1-29.

[32] International Telecommunication Union ITU-D, "ICT Data and Statistics (IDS)", World Telecommunication/ICT Indicators Database, 2011, available online under: http : //www.itu.int/ITU $-D /$ ict/.

[33] H. Claussen, I. Ashraf, and L. T. W. Ho, "Dynamic Idle Mode Procedures for Femtocells", Bell Labs Technical Journal, Vol. 15, No. 2, 2010, pp. 9511, DOI: 10.1002/bltj.20443

[34] International Telecommunication Union ITU-T, "Series G: Transmission Systems and Media, Digital Systems and Networks: GPON power conservation", Supplement 45, May 2009, pp. 1-46.

1 